\title{
ANALISIS NILAI INDEKS KEANDALAN SISTEM JARINGAN DISTRIBUSI UDARA 20 KV PADA PENYULANG PANDEAN LAMPER 1,5,8,9,10 DI GI PANDEAN LAMPER
}

\author{
Nur Indah Arifani, Heru Winarno \\ Program Studi Diploma III Teknik Elektro \\ Fakultas Teknik Universitas Diponegoro
}

\begin{abstract}
Nur Indah Arifani, Heru Winarno, in this paper explain that interruption of electricity supply for customers is very disturbing activity. Interruption/outage that occurred in the distribution network led to the disruption of continuity of service. Lots and duration of outages at the feeder Pandean Lamper 1,5,8,9, and 10 at Substation Pandean Lamper observed by the authors to get a reliability index value. This observation aims to get the value of SAIFI and SAIDI in substation feeder PDL Pandean Lamper at 1, 5, 8, 9, 10 and compared with a standard value of PLN as a world-class company (WCC) is SAIFI = 3 time/customer/year, SAIDI = 1.66 hours/customer/year. Disorders due to components and equipment as well as the tree is the most dominant cause of the outage. To obtain this index takes a data rate of failure ( $\lambda$ ), a long interruption (U) and the number of customers $(N)$ as well as get other customer-oriented index values are CAIFI, CAIDI, ASAI, ASUI. The analysis showed that the reliability index value for the feeder SAIFI value of PDL 1, 5, 8, 9, 10 all have a lower index value of PLN standards. For the fifth feeder SAIDI value only feeder PDL 9 impaired outages longer than four other feeder with an index value of 1.78 hours/customer/year beyond the PLN standard. For those who do not fit the standard feeder PLN performed maintenance measures components, as well as the supervision of the disturbance and other animals.
\end{abstract}

Keywords: distribution network, continuity, blackouts, interruption, SAIFI, SAIDI, CAIFI, CAIDI.

\section{PENDAHULUAN}

Kualitas energi listrik yang diterima konsumen sangat dipengaruhi oleh sistem pendistribusiannya.Untuk itu diperlukan sistem distribusi tenaga listrik dengan keandalan yang tinggi. Keandalan dalam sistem distribusi adalah suatu ukuran ketersediaan / tingkat pelayanan penyediaan tenaga listrik dari sistem ke pemakai /pelanggan.Ukuran keandalan dapat dinyatakan sebagai seberapa sering sistem mengalami pemadaman, berapa lama pemadaman terjadi danberapa cepat waktu yang dibutuhkan untuk memulihkan kondisi dari pemadaman yang terjadi.Sistem yang mempunyai keandalan tinggi akan mampu memberikan tenaga listrik setiap saat dibutuhkan, sedangkan sistem mempunyai keandalan rendah bila tingkat ketersediaan tenaganya rendah yaitu sering padam.

Bagian dari sistem tenaga listrik yang paling dekat dengan pelanggan adalah sistem distribusi.Sistem distribusi merupakan hal yang paling banyak mengalami gangguan, sehingga masalah utama dalam operasi sistem distribusi adalah mengatasi gangguan.Oleh sebab itu diperlukan pertimbangan dalam pengoperasian jaringan distribusi terhadap masalah keterandalan saluran distribusi

Pandean Lamper merupakan salah satu Gardu Induk penyuplai tenaga listrik bagi masyarakat Semarang Timur yang memiliki sepuluh buah feeder / penyulang.Dari dua penyulang yaitu penyulang Pandean Lamper 3 dan 4 menyuplai tenaga listrik ke Semarang Tengah, tiga penyulang lainnya yaitu Pandean Lamper 2,6, dan 7 melayani industri garmen dan TVRI. Selebihnya lima penyulang lainnya menyuplai tenaga listrik ke masyarakat.

Penyulang Pandean Lamper menjadi pengamatan pada tugas akhir ini, dengan data banyaknya dan lama gangguan atau pemadaman adalah sebagai berikut: Pandean Lamper 1 sebanyak 30 kali gangguan dan total menitnya 1915.Penyulang Pandean Lamper 5 sebanyak 34 kali gangguan dan total menitnya 3324.Penyulang Pandean Lamper 8 sebanyak 20 kali gangguan dan total menitnya 1110.Penyulang Pandean Lamper 9 sebanyak 57 kali gangguan dengan total menitnya 4645.Penyulang Pandean Lamper 10 sebanyak 34 kali gangguan dengan total menit 1701 (Sumber PLN Rayon Semarang Timur). Untuk mengantisipasi hal tersebut maka diperlukan suatu pengamatan untuk mengetahui sampai seberapa jauh indeks keandalannya.

\section{LANDASAN TEORI}

\section{Konsep Dasar Teori Keandalan}

Keandalan suatu peralatan atau sistem secara umum dapat didefenisikan sebagai probabilitas suatu alat atau sistem untuk menyelenggarakan tujuannya secara cukup untuk periode waktu tertentu dan kondisi operasi tertentu.

Terdapat empat faktor yang memegang peranan terhadap keandalan suatu sistem serta definisi keandalan mengandung empat istilah penting yaitu: 
- Fungsi, Keandalan suatu komponen perlu dilihat apakah suatu komponen dapat melakukan fungsinya secara baik pada jangka waktu tertentu. Kegagalan fungsi dari komponen dapat disebabkan oleh perawatan yang tak terencana (unplanned maintenance).Fungsi atau kinerja dari suatu komponen terhadap suatu sistem mempunyai tingkatan yang berbeda-beda.

- Probabilitas, angka yang menyatakan berapa kali gangguan terjadi dalam waktu tertentu pada suatu system atau saluran.

- Kecukupan performance, menunjukan kriteria kontinuitas suatu saluran sistem penyalur tenaga listrik tanpa mengalami gangguan

- Waktu, lama suatu saluran bekerja dengan baik sesuai dengan fungsinya. Semakin lama saluran digunakan, maka akan semakin banyak kemungkinan terjadinya kegagalan.

- Kondisi operasi, adalah keadaan lingkungan kerja dari suatu jaringan seperti pengaruh suhu, kelembaban udara dan getaran yang mempengaruhi kondisi operasi.

Faktor-faktor yang mempengaruhi indeks keandalan dalam suatu sistem distribusi sesuai standar IEEE P1366 antara lain :

- Pemadaman/ Interruption of Supply. Terhentinya pelayanan pada satu atau lebih konsumen, akibat dari salah satu atau lebih komponen mendapat gangguan.

- Keluar/Outage. Keadaan dimana suatu komponen tidak dapat berfungsi sebagaimana mestinya, diakibatkan karena beberapa peristiwa yang berhubungan dengan komponen tersebut.Suatu outage dapat atau tidak dapat menyebabkan pemadaman, hal ini masih tergantung pada konfigurasi sistem.

- Lama keluar/Outage Duration. Periode dari saat permulaan komponen mengalami outage sampai saat dapat dioperasikan kembali sesuai dengan fungsinya.

- Lama pemadaman / interruption Duration. Waktu dari saat permulaan terjadinya pemadaman sampai saat menyala kembali.

- Jumlah total konsumen terlayani / Total Number of Costumer Served. Jumlah total konsumen yang terlayani sesuai dengan periode laporan terakhir.

- Periode laporan. Periode laporan diasumsikan sebagai satu tahun.

\section{Laju Kegagalan ( Failure Rate )}

Menurut Sulasno (2001, h. 130), laju kegagalan adalah nilai rata-rata dari jumlah kesalahanpersatuan waktu pada selang waktu pengamatan waktu tertentu (T), dandinyatakan dalam satuan kegagalan pertahun. Pada suatu pengamatan, nilai laju kegagalan dinyatakan sebagai berikut :

$$
\lambda=\frac{f}{T}
$$

Keterangan:

(Sulasno,2001, h.130)

$\lambda=$ Laju kegagalan (kegagalan/tahun)

$\mathrm{f}=$ Banyaknya kegagalan selama selang waktu T)

$\mathrm{T}=$ selang waktu pengamatan (tahun)

Untuk menghitung lama gangguan rata-rata (Average Annual outage Time) :

$$
U_{S}=\frac{\Sigma t}{T}
$$

( Wilis, 2004, h. 110)

\section{Indeks Gangguan Berorientasikan Pelanggan}

Dalam penentuan indeks keandalan, untuk sistem secara keseluruhan maka faktor-faktor jumlah pelanggan, frekuensi dan durasi/ lama pemadaman dapat dievaluasi dan bisa didapatkan lengkap mengenai kinerja sistem.Indeks-indeks ini adalah frekwensi atau lama pemadaman rata-rata tahunan. Indeks keandalan yang dipakai pada sistem distribusi dijelaskan dalam uarain berikut ini.

System Avarage Interruption Frequency Index (SAIFI)

SAIFI merupakan suatu indeks yang menyatakan banyaknya gangguan (pemadaman) yang terjadi dalam selang waktu tertentu (1 tahun) pada pelanggan dalam suatu sistem secara keseluruhan.

$$
\begin{aligned}
\text { SAIFI } & =\frac{\text { Jumlah gangguan pelanggan }}{\text { Jumlah pelanggan }} \\
& =\frac{\Sigma \lambda_{i} \mathrm{~N}_{i}}{\Sigma \mathrm{N}} \ldots \ldots \ldots \ldots \ldots \ldots \ldots .(2.3)
\end{aligned}
$$

(Wilis, 2004, h. 111)

Keterangan:

$\lambda_{i}=$ laju kegagalan unit

$N_{i}=$ banyak pelanggan pada suatu titik.

\section{Costumer Avarage Interruption Frequency Index} (CAIFI)

CAIFI merupakan suatu indeks yang menyatakan banyaknya gangguan yang terjadi dalam selang waktu tertentu (1 tahun) padapelanggan dalam ruang lingkup yang lebih kecil.

$$
\begin{aligned}
\text { CAIFI } & =\frac{\text { Jumlah gangguan pelanggan }}{\text { Jumlah pelanggan terganggu }} \\
& =\frac{\Sigma \lambda_{\mathrm{i}} \mathrm{N}_{\mathrm{i}}}{\Sigma \mathrm{U}_{\mathrm{i}} N} \ldots \ldots \ldots \ldots \ldots \ldots \ldots(2.4)
\end{aligned}
$$

(Wilis, 2004, h. 111)

Keterangan:

$\lambda_{i}=$ laju kegagalan unit

$N_{i}$ =banyak pelanggan pada suatu titik.

$U_{i}=$ lama gangguan rata-rata 
System Avarage Interruption Duration Index (SAIDI)

SAIDI merupakan suatu indeks yang menyatakan lamanya gangguan (pemadaman) yang terjadi dalam selang waktu tertentu(1 tahun) pada pelanggan dalam suatu sistem secara keseluruhan.

$$
\begin{aligned}
\text { SAIDI } & =\frac{\text { Jumlah durasi gangguan pelanggan }}{\text { Jumlah pelanggan }} \\
& =\frac{\Sigma U_{i} N_{i}}{\Sigma N} \ldots \ldots \ldots \ldots \ldots \ldots \text { (2.5) }
\end{aligned}
$$

(Wilis, 2004, h. 112)

Keterangan:

$U_{i}=$ lama gangguan rata-rata

$N i=$ banyak pelanggan pada suatu titik

\section{Costumer Avarage Interruption Duration Index(CAIDI) \\ CAIDI merupakan suatu indeks yang} menyatakan lamanya gangguan yang terjadi dalam selang waktu tertentu (1 tahun) padapelanggan dalam ruang lingkup yang lebih kecil .

$$
\begin{aligned}
\text { CAIDI } & =\frac{\text { Jumlah durasi gangguan pelanggan }}{\text { Jumlah pelanggan terganggu }} \\
& =\frac{\Sigma U_{i} N_{i}}{\Sigma \lambda_{i} N} \ldots \ldots \ldots \ldots \ldots \ldots \ldots \text { (2.6) }
\end{aligned}
$$

(Wilis, 2004, h. 112)

Keterangan:

$U_{i}=$ lama gangguan rata-rata

$N i=$ jumlahpelanggan pada satu titik.

Avarage Service Availability (unvailability) Index (ASAI/ASUI)

ASAI merupakan suatu indeks yang menyatakan kemampuan suatu sistem untuk menyediakan/menyuplai suatu sistem dalam jangka waktu 1 tahun sedangkan ASUI merupakan indeks yang menyatakan ketidakmampuan suatu sistem untukmenyediakan/menyuplai suatu sistem.

$$
\begin{aligned}
\text { ASAI } & =\frac{\text { Jumlah jam pelanggan terpenuhi }}{\text { Jumlah jam seharusnya }} \\
& =\frac{\Sigma N_{i} \times 8760-\Sigma U_{i} N}{\Sigma N_{i} \times 8760} \ldots .(2.7)
\end{aligned}
$$

$\mathrm{ASUI}=1-\mathrm{ASAI}$

$$
=\frac{\Sigma U_{i} N}{\Sigma N_{i} \times 8760} \ldots
$$

(Wilis, 2004, h. 113)

Keterangan :8760 adalah jumlah jam dalam 1 tahun

\section{JALAN PENGAMATAN}

Jalan pengamatan atau pengumpulan data pengamatan adalah metode dokumenter. Langkahlangkahnya:

- Pengelompokan penyulang PDL 1,5,8,9, dan 10.

- Pengumpulan data pemadaman harian berupa data banyaknya /frekuensi dan durasi pemadaman dari tabel gangguan dan pemeliharaan pada penyulang PDL 1,5,8,9, dan 10.
- Merekap data banyaknya/frekuensi dan durasi pemadaman selama setahun dari bulan Januari s/d Desember 2012

- Membuat tabel frekuensi dan durasi pemadaman selama satu tahun berdasarkan rekapan data tiap penyulang.

- Membuat tabel pengamatan berdasarkan penyebab gangguan yang terjadi pada penyulang 1,5,8,9, dan 10 .

- Menghitung nilai indeks keandalan berupa SAIDI, SAIFI, CAIFI, CAIDI, ASAI dan ASUI.

- Menganalisa hasil perhitungan nilai indeks berdasarkan hasil penyebab gangguan.

\section{PEMBAHASAN}

Hasil pengamatan dan analisa yang telah dilakukan menggambarkan bahwa penyebab gangguan yang dominan pada GI Pandean Lamper khusunya penyulang $1,5,8,9$, dan 10 adalah adanya kerusakan-kerusakn dari komponen seperti SUTM putus, jumper SUTM rusak sedangkan pada gardu ditemui rusaknya isolator dan overload, juga akibat adanya gangguan alam seperti pepohonan.

Penyebab gangguan ini mempunyai peran dalam peningkatan keandalan sistem. Kinerja SAIFI maupun SAIDI ditentukan oleh banyaknya penyebab gangguan dan jumlah pelanggan yang padam, artinya satu kali gangguan yang menyebabkan pelanggan padam akan berpengaruh besar pada SAIFI maupun SAIDI (semakin buruk). Oleh karena itu langkah- langkah yang telah ditempuh untuk mengurangi jumlah gangguan adalah mengadakan analisa gangguan dengan tujuan untuk mencegah atau mengurangi kemungkinan terulangnya gangguan yang serupa.

Hasil analisa nilai indeks keandalan sistim distribusi menunjukkan bahwa frekuensi pemadaman yang terjadi pada penyulanng non industri PDL 1, PDL 5,PDL 8, PDL 9, PDL 10 pada gardu induk pandean lamper semuanya masih dibawah standar nilai SAIFI PLN sebagai perusahaan kelas dunia, namun nilai indeks lamanya pemadaman / SAIDI terdapat satu penyulang mempunyai nilai indeks diatas standar PLN. Penyulang pandean lamper 9 ini menggambarkan adanya gangguan gangguan yang terjadi yang mungkin dipicu oleh kejadian alam, ataupun kejadian-kejadian dijaringan itu sendiri. Untuk nilai Indeks CAIFI maupun CAIDI semuanya menggambarkan bahwa kontinuitas distribusi energi listrik baik dengan pengertian bahwa interupsi dalam hal frekuensi dan lamanya pemadaman dalam lingkup yang lebih kecil nilai indeksnya kecil dengan kata lain bhwa frekuensi dan lamanya pemadaman yang langsung dirasakan oleh pelanggan sangat rendah demikian pula respon sistem terhadap tingkat perbaikan kembali oleh system lebih cepat, hal ini ditunjukkan dengan nilai ASAI diatas $99 \%$. 
Secara keseluruhan tingkat gangguan/pemadaman pada penyulang khususnya PDL $1,5,8,9$ dan 10 pada SAIDI yang mempunyai nilai indeks diatas standar PLN sebagai perusahaan kelas dunia masih perlu diambil langkah-langkah seperti : pemeliharaan yang perlu diperhatikan untuk ditingkatkan yaitu pada komponen, Peralatan Gardu, tiang, pemangkasan pohon, kejadian kejadian alam, melakukan rekonfigurasi jaringan bila sangat diperlukan.

\section{KESIMPULAN}

- Nilai SAIFI untuk kelima penyulang tersebut semuanya masih memenuhi standar nilai yang telah ditentukan oleh PT PLN yaitu 3 kali pertahun, standar nilai SAIDI sebesar 100 menit / 1.66 jam yang digunakan oleh PT PLN sebagai perusahaan kelas dunia dalam hal pelayanan yaitu WCS (World Company service) dan WCC (World Class Company) dari lima penyulang di Pandean Lamper menunjukkan penyulang Pandean Lamper 9 yang memiliki nilai $1.78 \mathrm{jam} /$ pelanggan/tahun belum memenuhi standar nilai SAIDI, sehingga secara keseluruhan dapat dikatakan bahwa penyulang Pandean Lamper 1,5,8,9, dan 10 belum andal.

- Komponen-komponen serta peralatan terutama kabel SUTM, jumper SUTM, isolator dan trafo memerlukan perhatian untuk perawatan yang lebih intensif.

- Hasil analisa indeks berorientasikan pelanggan lainnya yaitu untuk nilai indeks CAIFI, CAIDI, ASAI dan ASUI menunjukkan bahwa semua penyulang memberikan kontribusi kemampuan yang sama pada suatu sistem untuk menyuplai dalam jangka waktu satu tahun, yaitu ASAI diatas $99 \%$ berarti respon sistem dalam mengatasi gangguan sangat cepat.

\section{DAFTAR PUSTAKA}

1. Anonim(http//www.pln.co.id/uiptet/?p=672) diunduh pada tanggal 23 Mei 2013 Pukul 21.00

2. Kadaffi, Muhammar. 2011. Perencanaan Sistem Distribusi Tenaga Listrik. Jakarta: Universitas Mercu Buana.

3. Pabla, A.S. 2007. Electrical Power Distribution fifth edition. New Delhi : Tata Mc Graw-Hill Publishing Company Limited.

4. Pulungan, Basrah. dkk. 2012. Keandalan Jaringan Tegangan Menengah $20 \mathrm{Kv}$ di Wilayah Area Pelayanan Jaringan (APJ) Padang PT PLN (Persero) Cabang Padang. Jurnal Nasioanal Teknik Elektro, Volume 1, Nomor1. Padang: Universitas Negeri Padang.

5. Saodah, Siti .2008. Evaluasi Keandalan Sistem Distribusi Tenaga Listrik Berdasarkan SAIDI dan SAIFI. Seminar Nasional Aplikasi Sains dan Teknologi. Yogyakata : Institut Teknologi Nasional.

6. Setyo Prambudhi. 2009. Analisa Penentuan Lokasi Dan Jumlah Sectionalizer Untuk Peningkatan Keandalan Sistem Distribusi. Surabaya: Institut Teknologi Sepuluh November.

7. Sudirham,Sudaryatno. 2006. Distribusi Energi Listrik .Bandung : Institut Teknologi Bandung

8. Sulasno.2001. Teknik Dan Sistem Distribusi Tenaga Listrik. Semarang : Universitas Diponegoro

9. Thayib, Rudyanto. 2011. Perhitungan Indeks Keandalan Sistem Tenaga Listrik Interkoneksi Sumatera Bagian Selatan. Seminar Nasional AVoER ke-3. Palembang: Universitas Sriwijaya.

10. Willis, H. Lee. 2004. Power Distribution Planning Reference Book Second Edition, Revised and Expanded, Raleigh, NortCarolina, U.S.A. New York-Basel: Marcel Dekker, Inc. 